\title{
Paper Strength Development with Beating and Polyamideamine-epichlorohydrin (PAE)
}

\author{
Maria Ulfa ${ }^{1,2 a}$, Bambang Setiaji ${ }^{3}$, Wega Trisunaryanti ${ }^{3}$, Triyono ${ }^{3}$ \\ ${ }^{1}$ Doctoral student of Chemistry Dept. of Gadjah Mada University, Yogyakarta, Indonesia \\ ${ }^{2}$ Chemistry Dept. of Mataram University, Mataram, Indonesia \\ ${ }^{3}$ Chemistry Dept. of Gadjah Mada University, Yogyakarta, Indonesia \\ ${ }^{\mathrm{a} E m a i l:}$ rafif_ali@yahoo.com
}

Received: 10 September 2015, Revised: 30 February 2016, Accepted: 26 August 2016

\begin{abstract}
Thecharacter of coir handsheets prepared with beating and addition of polyamideamine-epichlorohydrin (PAE) was investigated. Pulp coir from soda-anthraquinone pulping was used as raw material for manufacture of coir handsheets. Physical and mechanical properties obtained with different beating level and PAE dosage were measured. The addition of PAE $10 \% \mathrm{w} / \mathrm{w}$ and beating on pulp stock of $3000 \mathrm{rev}$ increased grammage and density at 1.9 and $15.8 \%$, respectively. Instead it decreased thickness by $15.8 \%$. Addition PAE dosage of $10 \% \mathrm{w} / \mathrm{w}$ at $10000 \mathrm{rev}$ improved the density, but decreased the porosity and $\mathrm{Cobb}_{60}$ at $5.8 ; 10.2$; and $19 \%$, respectively. The highest dry and wet tensile were obtained at $20 \% \mathrm{w} / \mathrm{w}$ of PAE. Combination of beating and addition of PAE on pulp stock formed wet-strength handsheets with range between 28.0 to $34.2 \%$.
\end{abstract}

Keywords : coir, handsheets, beating, Polyamideamine-epichlorohydrin, wet-strength

\section{INTRODUCTION}

Coir pulp that produced soda-anthraquinone process containslignin $(>30)$, which affect the quality of the paper, e.g. degree ofbrightnessand mechanical properties(Joedodibroto, 1990). Mechanical properties of papercould be improvedphysically and chemically. Physically, development of mechanical properties could bedoneby refining or beatingfibers. This treatmen timproves the internal and external fibrillation in the fiber that form a better fiberto-fiber bonding on handsheet (Gao et al., 2012). Addition wet-strength additive on stock pulp was chemically to improve the mechanical properties (Su et al., 2012). To lessen the reduction of paper strength upon contact with water, reactive water-soluble polymers such as polyamideamine-epichlorohydrin (PAE) are commonly used to improve the bonding between fibers, which contitutes the weak link in wet paper (Davison, 1972). According to Suet al. (2012), the additionof PAE on the stock pulp of eucalyptusthat has beenbleached increased the mechanical propertiesof paper, especiallywettensile index.

Beating process of coirpulpin this studywas awet methodusing water. This methodcausessomephysical changes infibersuch asthe formation of fines whichfacilitated theswelling offibersdue tothehydrophilic of fiber; fiberswere moreflexible; fibercut off; andoccurs fibrillation external and internal(Mohlin, 1995; MohlinandDaniel, 2004).

This studyaims toassess the effect ofwet-strengthadditive (PAE)andbeatingonthe physicaland mechanicalproperties ofcoirhandsheets.

\section{MATERIALS AND METHODS \\ Materials}

Coir fibers that contain free pith $( \pm 15 \%$ moisture content) were weight and charged into the tube digester capacity of $3 \mathrm{~L}$ with the require amount of chemical solution at a liquor 
to solid ratio $8: 1$. The digester was heated to the operating temperature $\left(160{ }^{\circ} \mathrm{C}\right)$ and time $(90$ $\mathrm{min})$. As for concentration of cooking liquors were added $15 \% \mathrm{NaOH}$ and $0.15 \%$ AQ (w/w, based on o.d.w). The resulting pulp thoroughly washed with tap water to avoid chunks of fiber (fiber bundles). Further pulp milled and pressed to remove the water content in pulp. The pulp was transferred to disintegrator (Model MKIIIC, Messmer Instruments Ltd) diluted to $2 \mathrm{~L}$ with deionized water, and disintergrated for 75,000 propeller revolutions.

\section{Methods}

\section{Handsheets preparation}

Coir handsheets were prepared according to TAPPI standard method T 205 sp-95.

Basically, the stock of coir pulp have beendisintergrated forall variations ofbeating level(0, 750, 1500, 3000and10000rev). Prior to handsheet forming, the PAE solution was added to pulp slurry $(0,10$ and $20 \mathrm{mg} / \mathrm{g})$. The addition quantity of PAE was based on oven dry grammage of previously refined pulps were then used to prepare coir handsheets with grammage of $60 \mathrm{~g} \cdot \mathrm{m}^{-2}$. After manual and couching and wetpressing at $0.4 \mathrm{MPa}$ for about 15 seconds, the sheet were cured in a drum-dryer at $100{ }^{\circ} \mathrm{C}$ for $10 \mathrm{~min}$, in order to activate the bonds between the PAE and the cellulose surface.

\section{Characterization}

The important strength properties of coir handsheets performed in this study were dry and wet tensile strength (TAPPI T494 om-01). An Instron tensile tester (Instron 5566) was used to record maximum tensile force with constant rate of elongation at $10 \mathrm{~mm} / \mathrm{min}$. The morphology of the obtained handsheets was observed using a Phenom Scanning Electron Microscope (SEM). Each sample was prepared with a gold/palladium coating before the analysis. Then, grammage (TAPPI T 410 om08), thickness (TAPPI T 411 om-10), density (TAPPI T426 wd-70) were measured. Porosity (Bendtsen method) on paper made reference to the standard TAPPI T547 om - 02 .

\section{RESULTS AND DISCUSSION Physical properties}

Grammage of handsheets obtained in this study ranged from 58.98 to 66.18 g.m² (Fig. 1). The highest grammage was produced by the combined treatment of addition of PAE $20 \%$ $\mathrm{w} / \mathrm{w}$ and beating level $3000 \mathrm{rev}$ (an increase of $3.57 \%$ from the grammage of handsheet at a PAE concentration of $0 \%$ ). The addition of PAE increased grammage due to higher concentrations of PAE.

Fig. 1 shows addition PAE dosage of $10 \%$ $\mathrm{w} / \mathrm{w}$ and beating level of 750 rev has grammage
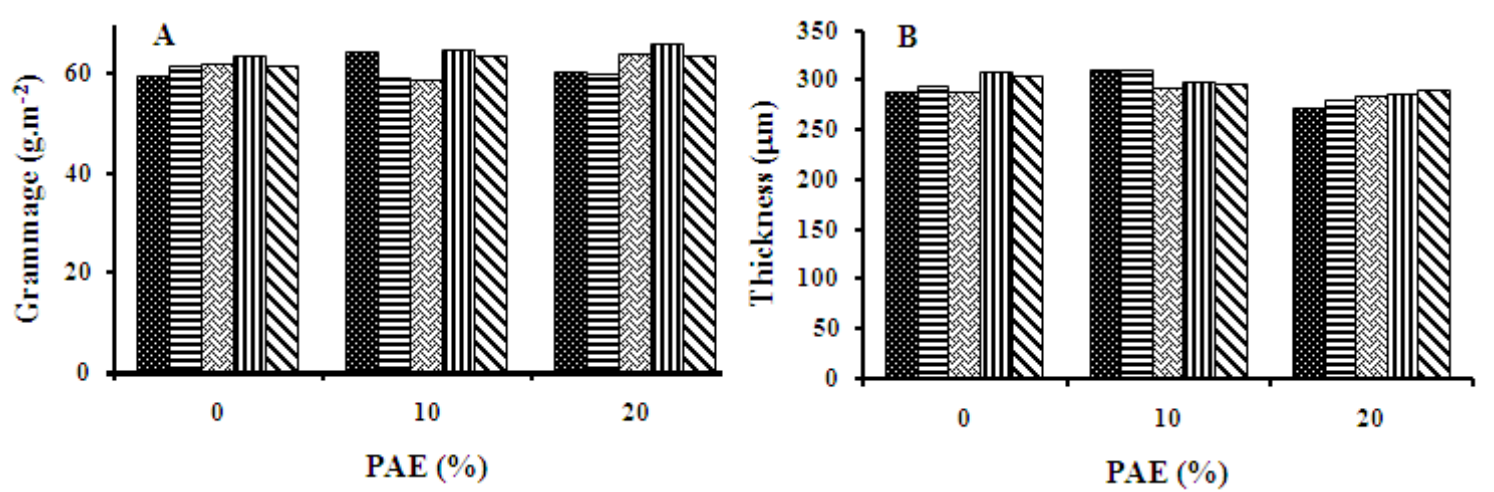

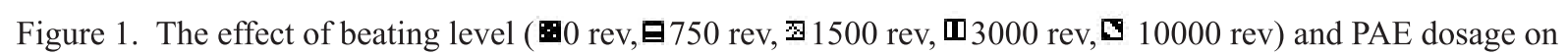
grammage (A) and thickness ( B ) of coir handsheets 
that below target but the highest thickness $(311.2 \mu \mathrm{m})$. This shows the beating level not enough affected individual fiber shorten, reduce cell wall thickness, and fibrillation. Addition PAE dosage of $10 \% \mathrm{w} / \mathrm{w}$ and beating level of 3000 rev increased the grammage and decrease the thickness at 1.9 and $3.5 \%$, respectively. This means that an increase PAE dosage increased the density of handsheets $(15.8 \%)$ as seen in Fig. 2).

The thickness of the handsheets highly influenced by the amount and distribution of fibers on the plane of handsheet or the thickness is directly proportional to grammage. However, the thickness of the handsheets decreased with the addition of PAE. The fines together with PAE filled the gap in the plane of the handsheets with co-crosslinking and homo-crosslinking (Fig. 3) so that handsheets display were thinned with increasing PAE dosage.
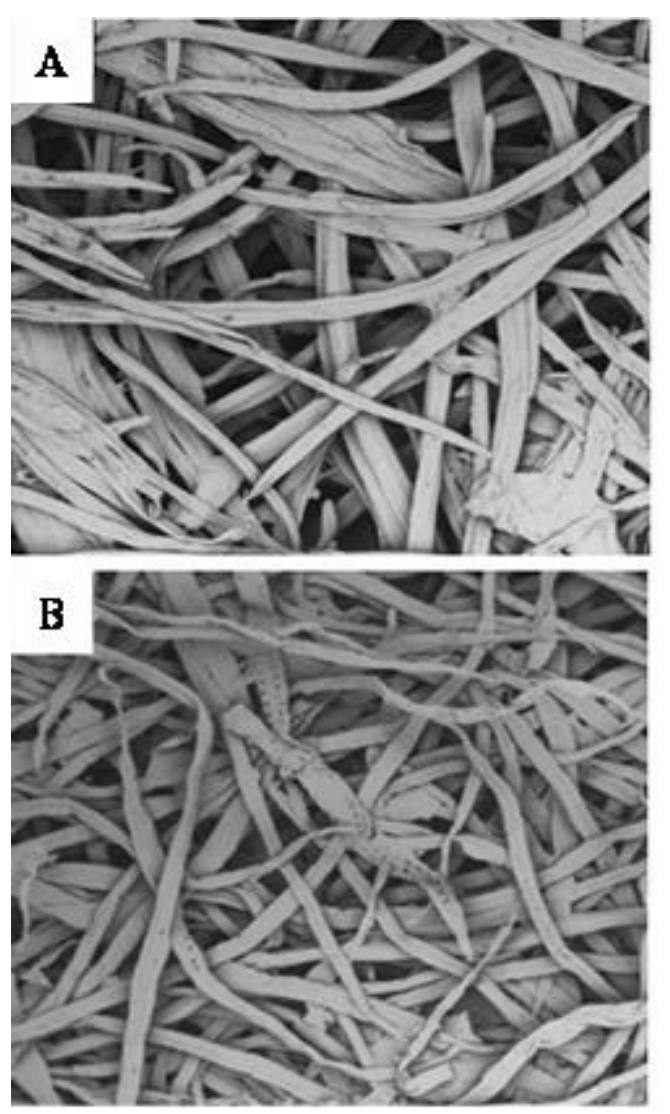

Figure 3. Morphology of coir handsheet before $(A, C)$ and after $(B, D)$ addition of PAE (A and B 500× magnification; C and D 1000× magnification)

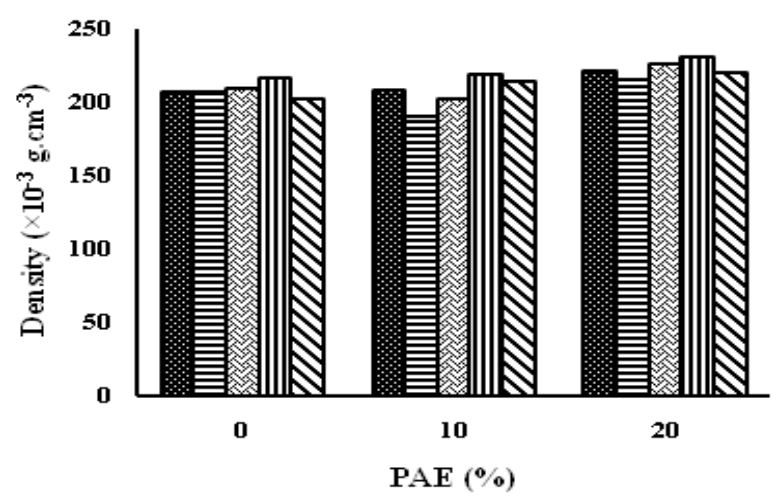

Figure 2. The effect of beating level ( 0 rev, $\mathbf{\Xi 7 5 0}$ $\mathrm{rev}, \boldsymbol{\nabla} 1500 \mathrm{rev}, \boldsymbol{D} 3000 \mathrm{rev}, \mathbf{\nabla} 10000 \mathrm{rev})$ and PAE dosage on density of coir handsheets

The porosity of handsheets is closely related to density and ability to absorb water which is expressed by the value $\mathrm{Cobb}_{60}$. Over beating level (10000) affected more individual fiber cut and shorten. Handsheets composed of short sized fiber bonding increased the surface area of absorption or has a low density
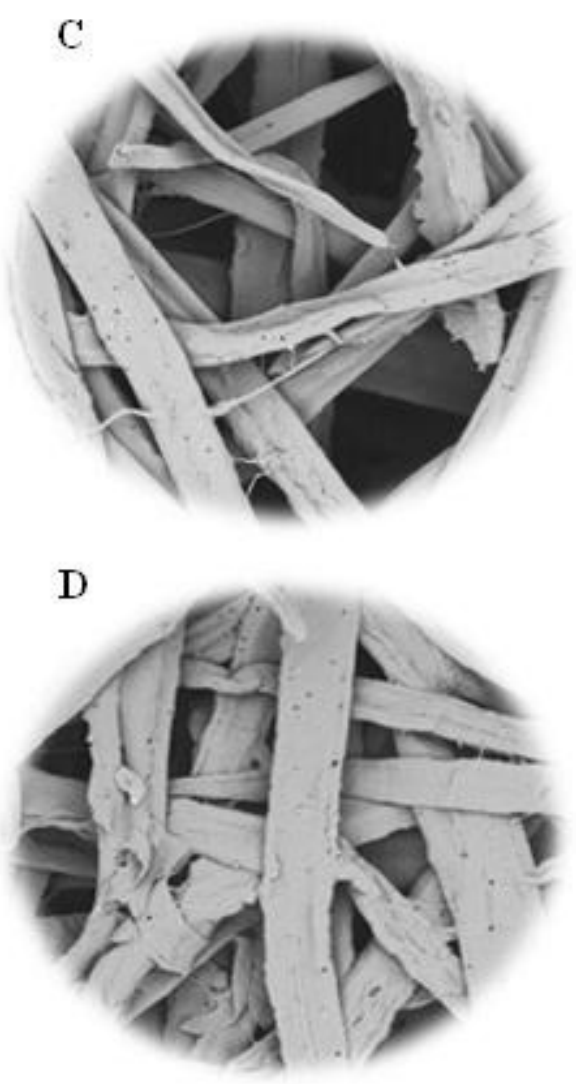

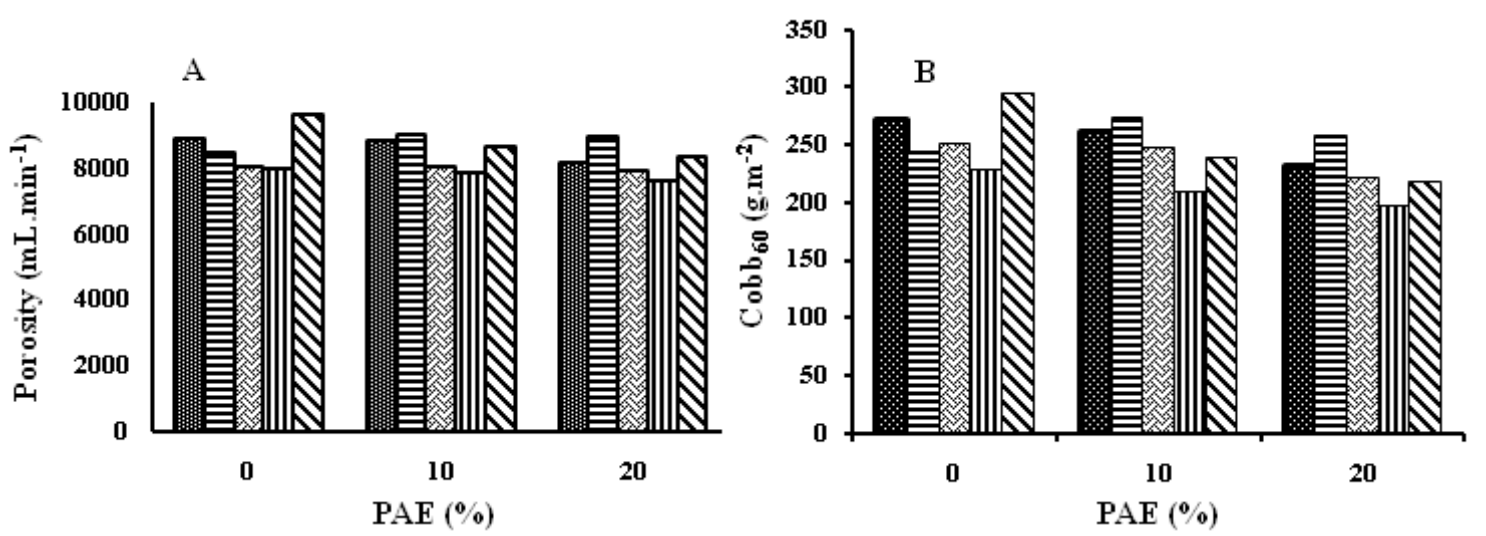

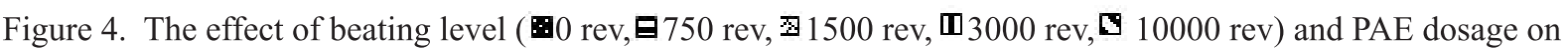
porosity (A) and $\mathrm{Cobb}_{60}(\mathrm{~B})$ of coir handsheets
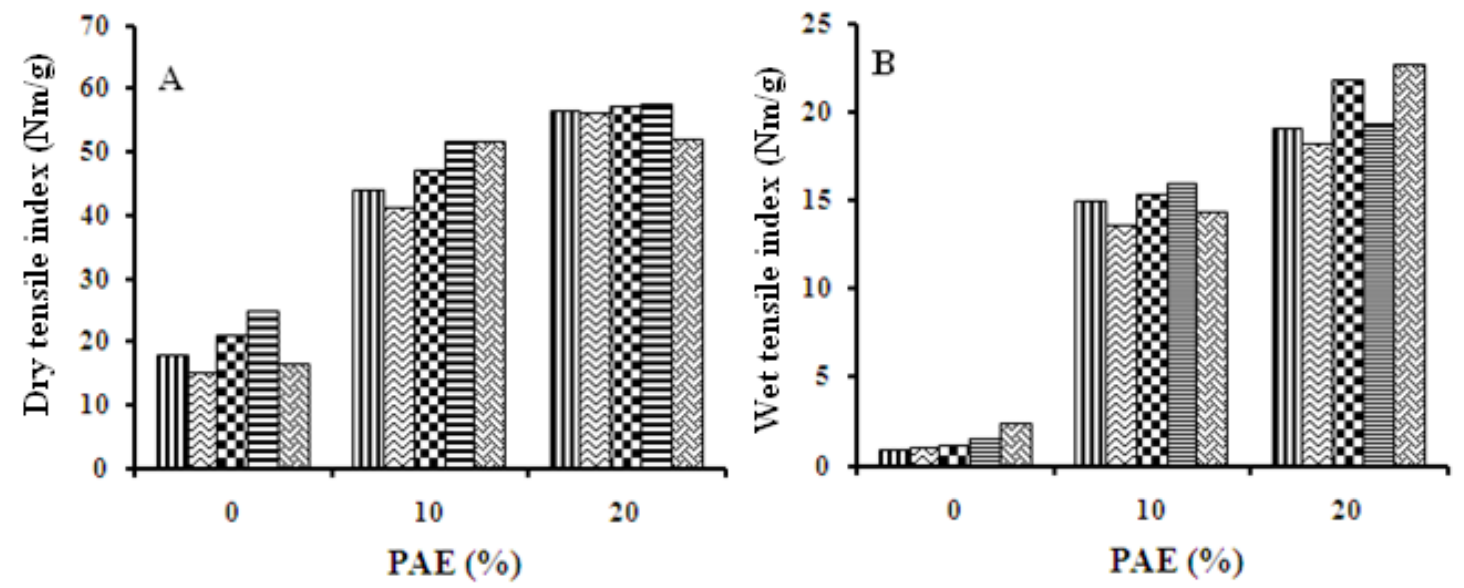

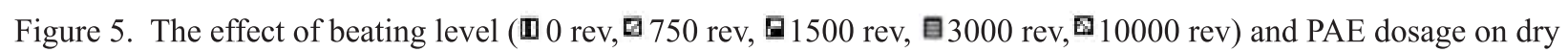
tensile index (A) and wet tensile index (B) of coir handsheets

and a high porosity and $\mathrm{Cobb}_{60}$. Addition PAE dosage of $10 \% \mathrm{w} / \mathrm{w}$ improved the density, lower porosity and $\mathrm{Cobb}_{60}$ at 2.3 ; 3.4 ; and $19 \%$, respectively ( Fig.4).

\section{Mechanical properties}

The range of dry tensile index of coir handsheet was 15.24-57.70 Nm/g (Fig. 5A). The highest dry tensile was $57.70 \mathrm{Nm} / \mathrm{g}$ at PAE dosage of $20 \% \mathrm{w} / \mathrm{w}$ and $3000 \mathrm{rev}$. Meanwhile, the highest wet tensile index was $22.67 \mathrm{Nm} / \mathrm{g}$ at PAE dosage of $20 \% \mathrm{w} / \mathrm{w}$ and $10000 \mathrm{rev}$. Combination of beating and addition of PAE on pulp stock formed wet-strength handsheets with range between 28.0 to $34.2 \%$.
Figure 5 shows both graph demonstrate that when adding PAE continues to raise. The mechanical properties will develop until the saturation point and drop when adding PAE continues. Wet-strength development of PAEcontaining cellulose sheets is primarily ascribed to the ester bond formation between azetidinium groups of PAE and carboxyl groups of cellulose fibers (co-crosslinking), i.e. the covalent bond formation. The decrease in paper strength at high PAE dosage could be attributed to homocrosslinking of PAE, which was very sensitive to water and is weaker than the co-crosslinking of PAE and fibres (Bates, 1969; Espy and Rave, 1988; Obokata and Isogai, 2007). 


\section{CONCLUSION}

The effect of beating and the ability of Polyamideamine-epichlorohydrin (PAE) to improve physical and mechanical properties were investigated by preparing handsheets with coir pulp. The addition of PAE dosage of 10 $\% \mathrm{w} / \mathrm{w}$ at $3000 \mathrm{rev}$ improved grammage and density but decreased the porosity and $\mathrm{Cobb}_{60}$. The maximum enhancement of dry and wet strength properties was achieved at different beating levels and the same as PAE dosage. Combination of beating and addition of PAE on pulp stock formed wet-strength handsheets with range between 28.0 to $34.2 \%$.

\section{ACKNOWLEDGMENT}

The financial contribution of DIKTI research programs of Indonesia and APPIChemical Engineering Departement-Monash University are acknowledged.

\section{REFERENCES}

Bates, N. A. (1969). Polyamide-epichlorohydrin wet-strength resin: A study of mechanism of wet-strengt development in paper. Tappi, 52(6), 1162-1169.

Davidson, R. W. (1972). Weak link in paper dry strength.Tappi, 55(4), 567-573.
Espy, H. H., \& Rave, T. W. (1988). The Mechanism of wet-strength development by alkalinecuring amino polymer-epichlorohydrin resins. Tappi Journal, 71(5), 133-137.

Gao, W. H., Chen, K. F., Yang, R. D., Yang, F. \& Han, W.J. (2011). Properties of Bacterial Cellulose and Its Influence on The Physical Properties of Paper. BioResources, 6(1), 144153.

Mohlin, U.B. (1995). Fiber Development in Mechanical Pulp Refining, Proceeding on The 1995 Mechanical Pulping Conferences, 6-10 May 1995, Stockholm.

Mohlin, U. B. \& Daniel, G. (2004). Effects of Refining on The Fibre Structure of Kraft Pulps as Revealed by SEM and TEM: Influence of Alkaline Degradation. Holzforschung, 58(3), 226-232.

Obokata, T., \& Isogai, A. (2007). The Mechanism of Wet-Strength Development of Cellulose Sheets Prepared with PolyamideamineEpichlorohydrin (PAE) Resin. Colloids Surf., A, 302, 525-531.

Su, J., Mosse, W.K.J., Sharman, S., Batchelor, W. \& Garnier, G. (2012). Paper Strength Development and Recyclability with Polyamideamine-Epichlorohydrine (PAE), . BioResources, 7(1), 913-924. 